\title{
Between Chaos and Entropy: Community of Inquiry from a Systems Perspective
}

\author{
NADIA STOYANOVA KENNEDY \\ Stony Brook University (United States) \\ DAVID KENNEDY \\ Montclair State University (United States)
}

This paper considers the psychosocial and cognitive dynamics of an educational community of inquiry as an inquiring system. It identifies seven characteristics of social systems dedicated to inquiry that are open (as opposed to "control" systems)-autopoiesis, teleology, feedback, noise, redundancy, ambiguous control, and system "event"-and traces their function in the ongoing reconstruction of argument that collective, dialogical inquiry entails. The paper also analyzes the process of group inquiry from a dialectical perspective, interpreting conceptual and argumentation system development as a continuously emergent process of reorganization, which makes its way through the ongoing resolution of the oppositions and contradictions it encounters, resulting in greater organizational complexity and clarity. Rather than maintaining homeostatic stability by rejecting or resisting noise, it develops through accepting and incorporating it in the interest of dialectical emergence. The role of a facilitator in such a system is to provide both positive and negative feedback, navigating between system entropy and system chaos. Finally, the autopoietic inquiring system is offered as one exemplar of the "ideal speech situation," which requires that all its members have equal opportunity to participate in and contribute to system emergence, free from internal constraints or external coercion. This implies the need for a pedagogy that not only develops communicative competence, but which models a form of argumentation that understands itself as a collective project of ongoing reconstruction-with the major goal of agreement arrived at through open, free communication. 


\section{Community of Inquiry as a Pedagogical Model}

The term "community of inquiry" (CI) is widely employed in educational circles, and is used to describe a variety of pedagogies and curricula. Understood generically, CI is one kind of community of interpretation (Corrington, 1994, 1987) which we understand as a spontaneous human discourse form - that is, a group of persons engaged in making new meaning together. A drum group could be described as a community of interpretation, or a séance, or group psychotherapy, or even a dance or meditation circle, not to speak of a committee meeting. Our use of the term refers directly to the particular classroom discourse model initiated in the 1970's as a pedagogical method by Matthew Lipman in his Philosophy for Children program, which was designed specifically for critical discussion of "purely" philosophical concepts (Lipman, Sharp \& Oscanyan, 1980; Sharp, 1992; Splitter \& Sharp, 1995; Lipman, 2003). It can be traced genealogically to Socrates' group in the Athenian agora, which had the specific purpose of deliberating together about common, central and contestable concepts such as conflict, truth, justice, friendship, beauty and so forth, but in Lipman's formulation, draws on the "pragmaticist" epistemology of C.S. Peirce (1966) and John Dewey (1939), and identifies itself as an educational methodology capable of teaching critical thinking through actually doing it (Hand \& Winstanley, 2009; Kennedy, 2004b) in group dialogue form, and guided by an experienced facilitator.

Thus, although the term "community of philosophical inquiry" may better describe the discourse model we are concerned to investigate from a systems perspective, we avoid it here, primarily because our current research and scholarship is dedicated to extending the philosophical method-that is, critical analysis of classical philosophical concepts like those mentioned above - to inquiry and problem-solving within and across the academic disciplines, whether history, mathematics, or science. That is, we are interested in the application of the communal, dialogical, deliberative process as a setting, not just for inquiry into concepts such as infinity in mathematics, for example, or organism in biology, or progress in history, or health in physical education (Kennedy, 2006; Kennedy, 2007; Lipman, 2003), but for critical problem-solving activities as well. Our goal is to contribute to the opening of a space in schools for the philosophy of each discipline under study; but we are also interested in how the discourse model of CI can be adopted in any facilitated and structured group inquiry, whether or not it inquires into the meaning and application of a concept, or works at answering an "essential question" (Wiggins \& McTighe, 2005), addresses a conflict resolution issue, or works on solving a theoretical or practical problem-for example, mathematical problem solving carried out by a group of mathematicians or a group of students in a classroom.

By community of inquiry, then, we mean a relatively small (10-20) group of people engaged in a conversation (or, preferably, an ongoing series of conversations) about an agreed-upon concept or problem or question, which is convened and overseen by a "facilitator" who is committed to certain normative ideals, chief among which is the construction of an "ideal speech situation" (Habermas, 1990)-that is, a discursive setting in which everyone has equal right and opportunity to speak, in which intimidation of any sort is absent, and in which epistemological authority is distributed 
rather than centralized in one person. The facilitator is also committed to modeling and coaching participants in the performance of a sort of double vision, in the sense both of observing the famous Socratic autopoietic dictum of "following the argument where it leads" (the substantive), and also paying metacognitive attention to how the argument is proceeding and to what particular intervention would help it to proceed (the procedural). Finally, she is committed to the goal of fostering the distribution, not just of epistemological authority, but of procedural authority through the whole group. In other words, the facilitator is working toward the eventual distribution of her own role among the participants, such that each member of the group-as-a-whole is capable of maintaining the double vision and thus acting to influence the autopoeitic process in an optimal way. Our interest in reflecting on the structure and dynamics of such an open social, communicative, argumentation system is driven in great part by the conviction that it represents a significantly different discourse model from the traditional school classroom's - above all one that immerses students and teachers in a social habitus of epistemological curiosity, critical consciousness, non-authoritarian power relations, and authentic democratic practices.

We understand the process of $\mathrm{CI}$ as dialogical and dialectical-the former in that it depends for its success on a commitment by each member to the interrogation of one's own beliefs and assumptions as well as of others'; the latter in that it moves forward through the emergence and attempted resolution of the contradictions both within and between assumptive frameworks. Since we are describing a pedagogy, our observations are based on both descriptive and normative assumptions; our gaze is directed both at what CI feels like or appears to be as a spontaneous social performance, and what it should or could be as a "successful" epistemological and communicative event-that is, what it is and what we can make of it as a form of pedagogical action. In our attempt to navigate the sometimes treacherous boundary between the descriptive and the normative, we will first offer a brief characterization of the regulative ideals of $\mathrm{CI}$, and then move to a more formal analysis of the $\mathrm{CI}$ discourse model as an autopoietic system per se. We will then attempt to trace the particular characteristics of $\mathrm{CI}$ that indicate risk or opportunity for system transformation from the point of view of communications theory and systems theory in general. Finally, we will reflect briefly on the implications of the implicit conflict of models - open system versus control system-for education in a social system that at least aspires to genuine democracy.

\section{Some Distinctives of a Community of Inquiry}

The main objective of $\mathrm{CI}$ is to undertake the problematization, deconstruction, and consequent reconstruction of assumptions and the beliefs that ground them, not through transmission, individual reflection or debate, but through "building on each other's ideas" - that is, through distributed thinking in a dialogical context. This exercise in thinking for oneself and with others is understood to advance through the giving and the justifying of reasons. Each reasoning move represents an adjustment of the collective "argument" - that is, of the whole structure of judgments in place at that moment- 
offered in the interest of a state of adequation, agreement or coordination of perspectives which, given that it is an open system, is in fact never arrived at (Kennedy, 2004a). By reasoning moves, we mean the interventions that can be found in any list of critical thinking skills-for example clarifying terms or ideas, offering examples and counterexamples, identifying assumptions, making careful inferences, stating hypotheses, identifying consequences, looking for missing perspectives, and so forth (Kennedy, 2008).

The ideal inquiry proceeds dialectically, in the sense that it moves forward through encountering and attempting to resolve tensions or contradictions between and within ideas. The chief pedagogical significance of the CI process is that it operates in a collective zone of proximal development, which acts to "scaffold" concepts, skills and dispositions for each individual. The scaffolding process functions through subprocesses such as clarification, reformulation, summarization, and explanation, as well as through challenge and disagreement. The problematization, deconstruction and reconstruction of a concept-"conflict" for example-proceed by following the inquiry where it leads through a communal process of posing questions, exploring alternatives and hypotheses, asking for evidence, criteria and reasons, connecting and distinguishing ideas, and drawing temporary conclusions. A discussion about "conflict" may start, for example, by exploring two hypotheses like "Only living organisms can be in conflict," and "There can be conflict between machines such as computers." "Following the argument where it leads" will require attempts at definition, examination of examples and counterexamples, identification of criteria, and the drawing of provisional conclusions. Through this process, interlocutors build - and model for each other-not just reasoning skills per se, but skills in translating between various expressive, cognitive and discursive styles and registers. And because the model is understood as nonhierarchical, democratic, pluralistic, ethically sensitive, and oriented to individual and communal transformation, implicit (and sometimes explicit) emphasis is placed on the capacity to remain sensitive to context and to the beliefs of others, to put ego in perspective, to tolerate ambiguity, and to remain open to both individual and group selfcorrection.

As we have already pointed out, one important element of the discursive model presented here is the presence of a group facilitator who oversees the inquiry process. The facilitator neither forces the inquiry to predetermined ends, nor attempts to validate every opinion. She understands herself as a co-inquirer with the other participants, and as someone who guides, models and coaches inquiry through restating, asking for clarification, identifying connections between ideas, summarizing, and posing alternative views. The facilitator is less likely, for example, to ask substantive questions like "If a conflict is not...., is it ..?, and more likely to ask clarification questions such as: "Tom is saying that conflict can be ...., do you think his view is different from Ann's, and if so how?" As a rule, the facilitator is vigilant in enforcing procedural rulestypically concerning fair and equitable participation-and at the same time she remains philosophically self-effacing - that is, careful not to advance her own ideas as having more weight because of her authoritative role in the group. Her regulative ideal is that 
both the argumentation and the procedural moves that she is modeling be internalized by each member and thus distributed through the group, such that eventually the group becomes self-facilitating as a democratic discourse community.

In systems theory terminology, community of inquiry may be broadly identified as an aggregate of living systems - in this case, individual humans-and a system itself, whose most distinctive characteristic is the capacity for self-organization or autopoiesis (Von Bertalanffy, 1968; Maturana \& Varela, 1980; Luhmann, 1995). The autopoietic function is rooted in the dynamics of the interactions between the individual constituents, which inform the epigenesis of the systemic structure as a whole (Varela, Maturana \& Uribe, 1974). ${ }^{1}$ The structural organization of such a system, which is a recursive function of its constituents, is therefore of necessity an emergent one. In addition, a community of inquiry is a holder or container of knowledge-producing structures-which can be described as established procedures for reasoning, communication, problem-solving, and concept-interrogation.

\section{Community of Inquiry as a Social (Inquiring) System}

We assume that $\mathrm{CI}$ is: 1 ) an open system - i.e. that it interacts with the environment, and thus is able to alter its own content and structure as well as that of its environment (Hall \& Fagan, 1975); and 2) a social system in which there are no constituents that attempt to exercise control over others through coercive power, including disciplinary power, which acts to control individuals through ranking, surveillance, and normalization (Foucault, 1979; Habermas, 1990). The organization of any open social system, and therefore any $\mathrm{CI}$, is contingent both upon the participation of each member and on communication within its environment (Kuhn, 1975). The components of the system realize themselves through their participation in the system, and the system's autopoietic properties are manifested as a complex of processes oriented both towards conserving the system and towards reconstructing or improving it. That is, the participants-themselves the constituents of the system-are concerned as much with the preservation of the system and its function as with its change and reconstruction, and the individual's vision for changing the system is constantly evolving, depending as it does on the meanings constructed within the system, and on the feedback mechanisms that keep the system in a state of optimal emergence.

In the case of open systems, feedback-a concept adopted from cybernetics-is a mechanism that works in much more complex ways than in control systems, since it provides for both conservation and structural reorganization through patterns of action and reaction between system members. So-called negative feedback arises either from inside the system or enters from without, and functions in support of maintaining

\footnotetext{
${ }^{1}$ While we are aware that (i) the application of autopoeitic theory, which is based on a biological metaphor, to social systems is a contested issue, and that (ii) whether a goal-oriented, directed or facilitated system can be considered autopoeitic at all is contestable as well, it is not within the scope of this paper to take up these issues. For a discussion of issues of control in complex learning systems see Davis \& Simmt, 2003, p.152-154
} 
system stability, while positive feedback operates as a producer of change; that is, it may help the system to reinforce a given tendency, and in that way lead the system away from an equilibrium state, and therefore cause unexpected results (Ford \& Lerner, 1992). As such, the constructive, self-preserving, and reconstructive properties of such systems are realized through recurrent both positive and negative feedback interactions between its constituents.

The facilitator's feedback role is mainly to provide reactions to the other participants' moves-which in the cybernetics lexicon would be characterized as negative feedback, since it plays a corrective, conservative role. Examples of negative feedback would be instances in which the facilitator enforces the procedural rules of sticking to the point, listening to each other, and not interrupting. In other cases, she triggers or suggests alternative interpretations or standpoints, which can be characterized as positive feedback, since it is aimed at increasing variety in the system. The facilitator also attempts indirectly to mediate between different positions. Such a move or sequence of moves represents feedback that forces constructions of new meanings in the system. An example of positive feedback would be an instance in which a participant's intervention-for example, a question that is seemingly unrelated to the current inquiry-is acknowledged and marked as interesting by the facilitator, who foresees that it might challenge the positions at hand, and function as a potential trigger for reshaping ideas and conclusions. Feedback in CI is thus a complex and dynamic combination of positive and negative instances, both of which drive the growth of the system, and contribute directly to its self-organization.

Although the sort of inquiring system under analysis here can be characterized as open, its dynamic possibilities will necessarily be affected by the fact that it is embedded in larger systems - in this case the school, the system of families involved with the school, and the various domains of the educational system in general (for example, curriculum norms, general ideas of "best teaching practice," values about "authentic assessment" and so on)-which are in the great majority of cases control systems. Furthermore, CI is not just an inquiring system but a social system, and as such, according to Maturana (1988), is a network of coordinated constituents' interactions in a domain of "collective acceptance." The elements of a domain of collective acceptance may range from accepted discourse patterns, facilitation or questioning techniques and other reflective practices, to gestures, group rituals, or accepted sitting arrangements in a circle, for example. Another important characteristic of the system is its teleological property, in the sense that it has adopted inquiry as a paradigm for the purposeful pursuit of certain goals. Finally, human social systems are networks of coordinated actions in language - they are networks of diverse conversations. Change in a social system is realized as conversational change; that is, it occurs through "languaging" (Maturana, 1988; Maturana, Varela, 1987).

A social inquiring system is realized in multiple semiotic dimensions, including at least the psychological, cultural, communicative, argumentative and cognitive, and as such is a complex of interconnected subsystems, all of which are interactive, and which intersect and even overlap. Argumentation, for example, is a subsystem of the 
communicative network, and is itself a nexus of coordinated actions. The domain of argumentation is demarcated by members of CI through defining acceptable argumentation rules and practices such as supporting conclusions with reasons, and connecting one's inference to ones previously made. A combination of analytic categories from communications theory and systems theory can be applied in order to analyze argumentation as a subsystem, and to characterize its changes.

For example, Shannon \& Weaver's (1964) concept of noise-understood as an obstacle that stands in the way of a message, and which might manifest as ambiguity, error, or distortion - is of particular significance to the communal inquiry process. When noise is introduced into the communicative system, certain extraneous material appears, which results in an increase in uncertainty. Noise lowers the likelihood of a certain message "getting through." On the other hand, from the point of view of CI, communication without noise is not possible, given that all signs and messages are modified-i.e. rendered more uncertain-once they enter the communicative matrix (Corrington, 1987). According to Corrington, a community of inquiry is synonymous with a "community of interpreters," and no interpreter takes over a sign without an alteration of the original semiotic material (Corrington, 1994). In the inquiring system, a message received is never returned in its "authentic" form, but is handed back to the collective subject restated, reformulated, or somewhat altered, either on the syntactic level, the semantic level, or both, and therefore functions differently on the pragmatic level.

Given these essential characteristics of the communicative process, effective communication within the inquiring system requires a special emphasis on noisereducing strategies such as relating current interventions to preceding ones, formulating concepts carefully, questioning, clarifying, giving and asking for reasons, evaluating arguments and examples, and identifying fallacies and contradictions. In that the communicative and the argumentation subsystems are interactive and mutually informative, it can be assumed that these forms of communicative practice, when successful, serve to trigger positive change in the argumentation subsystem. The latter assumes a more adequate form and content-i.e. more and better coordinated moves and arguments - by virtue of more adequate moves on the syntactic (understood here as the broader syntax of arguments), semantic, and therefore pragmatic levels. On the other hand, the argumentation subsystem assists the communicative subsystem through applying new and more adequate patterns of connectedness and alignment in the sequence of arguments, and improved forms of argument-construction-all of which contribute to the clarity and sophistication of the communicative process on its three levels.

As we have seen, the concept of "noise" might be evaluated differently by communication theories and systems theory, at least in the case of CI. The former advocates as a matter of principle for noise reduction, which is understood to reduce uncertainty, whereas the latter understands the ambiguity that necessarily accompanies the semiotic work of community of inquiry, as potentially beneficial. Given that communication theory, developed primarily to serve technical purposes, is concerned 
with "transmitting" information and with the "effect" of a message on the receiver in a pragmatic sense-i.e., with digitalizing information (Shannon \& Weaver, 1964; Ackoff, 1958) - it is understandable that it would consider noise on the syntactic and semantic levels to be undesirable. Indeed, in CI the uncertainty that syntactic and semantic noise introduces may in fact slow down the communicative processes, and make conceptual understanding difficult or impossible. On the other hand, the noise generated by the encounter with conceptual ambiguities or flat-out contradictions along the way of communal inquiry can benefit the communal argumentation process, in that such a situation represents a kind of "semantic well," which increases the possibility for alternative interpretations and richer, more complex meanings. This sort of positive ambiguity will be referred to here as semantic noise, and valued-at levels which the inquiring system can tolerate-as a trigger for further semantic work, and consequent conceptual development.

Understood as a pedagogy, CI is based on the broad goal of adding a critical dimension to cognitive group work, with the implicit objective of reducing both syntactic and semantic noise on the individual level. The skills and dispositions typically associated with critical inquiry - asking for clarification, paraphrasing, offering reasons, summarizing, and other critical dialogue moves-tend to reduce vagueness and ambiguity (Lipman, 2003). But in fact these sorts of moves, because they act to reveal and problematize assumptions, tend to create semantic noise on the systemic level, thus maintaining the inquiry "in the suspense of uncertainty," a state which, according to John Dewey (1910) actually goads it forward (p. 13). Dewey's epistemology of inquiry (1939) - and constructivist epistemology in general-would suggest that the process of dealing with noise on the group level is a dialectical one: it involves an ongoing process of encountering ambiguities, contradictions, and conceptual or definitional vagueness, and working to resolve or clarify them, fully aware that any resolution is a temporary one, which will hold only until another cognitive conflict presents itself.

In CI practice, noise can both be found in and introduced into the system, intentionally or not, by presenting information containing vagueness, ambiguity, or contradictions. In fact, semantic noise can be engineered through any form of problematization in the group dialogue-for example, through comparing different ideas, positions, definitions, one individual's understanding of a concept with another's, or a past understanding with a new one. Such noise infusion necessarily calls for clarification of definitions and operative meanings that have surfaced in the argument. Ideally, a facilitator would produce an optimal amount of noise-enough to trigger examination and clarification of ideas, but not enough to overwhelm the system with too much material for processing. A facilitator may, for example, infuse noise into a dialogue about the phenomenon of conflict by introducing what would typically be considered a "category mistake": is conflict possible between non-living things such as weather patterns? Is a thunderstorm, for example an example of conflict? Such a switch in semantic registers not only functions as a trigger in the argumentation subsystem, but it also affects the psychological subsystem by way of precipitating repeated crises of decision. Confronted with contradictions or differences in ideas and positions, 
participants have to make a judgment for themselves, given that they are participating in a distributive conversational event. Finally, the regulative ideals of CI frame the conversation as collective deliberation rather than competitive debate, which triggers the psychological subsystem quite differently than either debate, instruction or Socratic interrogation does, introducing elements of play, desire and the imaginary, which, in Vygotsky's view (1978), can be highly effective in the development of abstract thought, but also highly productive of noise.

Several more concepts associated with communication theory deserve attention in this context. Redundancy refers to the repetition of the same message, delivered in several different forms, although thought of as equivalent by the sender (Ackoff \& Emery, 1972). An example of a facilitator's redundancy move would be to request that a group member paraphrase another member's statement, or do so herself. On a mechanistic account of the phenomenon of sending and receiving a message, redundancy is viewed as unwelcome, but in a distributive system like community of inquiry, redundancy acts to reduce semantic noise by allowing those deliberating on a message to choose the formulation that best communicates it, thus helping to organize and clarify the argumentation subsystem as well. In this case, redundancy constitutes a deliberate strategy-usually modeled first by the facilitator and later internalized by the participants - in the form of clarifications, reformulations, and summarizations.

\section{Steering Between Chaos and Entropy}

We have argued that the dynamics of the communicative system that is CI operate as a complex function of the members' coordinated actions, influenced by processes such as noise triggering, noise identification and reduction, redundancy, and various feedback patterns. Noise both triggers and escalates internal oppositions and contradictions in the system, and tends to call for resolution if it is understood by the system as noise; if it is not taken as noise, it may go unnoticed. In the evolution of natural systems, noise represents an intrusion into the system from outside which may trigger an escalation of pre-existing oscillatory or contradictory aspects of the system (Wilden, 1980). In cognitive systems, noise may be understood as a source or as a result of positive feedback leading to the emergence of difference, since it opens up the possibility of the appearance of new concept formations, one of which may challenge the current system and become what Wilden (1980) calls a system event-that is, an event which results in structural reorganization.

We can often see examples of such events in the form of conflicts between contradictory propositions or contradictory frames of interpretation, which act to bring about a reorganization of thought and meaning. Wilden (1980) describes a system event as a quantum leap in organization - "a passage from quantity to quality" (p.401). The emergence of difference heralds the appearance of qualitatively new forms through a synthesis of opposites-although the appearance of difference is not a sufficient condition for that emergence. In pursuit of that quantum leap, the facilitator may in fact feel led to introduce and amplify noise in the inquiring system (positive feedback) in 
order to encourage the felt need for semantic clarification, conceptual conflict resolution, and, hopefully, dialectical synthesis. In other cases, she may feel led to reduce system noise through clarification, restatement and the summarization of arguments as they stand at that moment. As such, the facilitator acts within the system both as both "trigger" (noise amplifier) and "bridge" (noise reducer) (Kennedy 2004b). She seeks to maintain a level of system arousal, in other words, that steers a course between chaos (noise overload) and entropy (absence of noise), disintegrative openness and stagnant closure.

She acts as a bridge by mediating between and-in Gregory Bateson's (1972) terminology - "punctuating" participants' interpretive frames, propositions, arguments and interpretations; she places each intervention in a discursive context that tentatively frames its emergent structure ("Amy is arguing that $\mathrm{x}$, and Paul that $\mathrm{y}$, and Laura has introduced the idea that . . ."). Her primary discursive tools are restatements, summarizations, and clarifying questions, all of which are indirect ways of aligning positions so that their similarities and/or differences become visible. This form of negative feedback is maintained both by the facilitator and the other participants, and also includes vocalizing and enforcing the procedural rules that encourage the ideal speech situation. The facilitator-and, as the community matures, all the participantscomment regularly on the procedural quality of the inquiry process, and typically end each session with a group evaluation. This second-order negative feedback - that is, articulating and applying the normative principles of the discourse-model to the model itself-works to develop individual self-regulatory feedback loops that work towards constraining the system and maintaining the system's rules.

On the other hand, the facilitator triggers the system through raising counterexamples and counter-claims, emphasizing certain elements of the argument, introducing new perspectives or questions when the inquiry seems to have lost direction, or making procedural suggestions-for example moving to a different question that is directly or indirectly related to the concept or problem under inquiry. In so doing, she is in fact providing positive feedback, which allows the system to recognize and entertain differences - a recognition necessary for system change. In providing both positive and negative feedback, she works both to keep the system stable and to change it, navigating always between the Scylla of potential system entropy and the Charybdis of system chaos. The negative feedback that the facilitator and the group members provide draws the group towards a state of homeostasis, which in some cases may be a zone of "flattened-out" conversation that narcotizes the group, drowns out "disturbing" issues and ideas, and establishes a consensus of indifference, in which no new ideas appear to be available. The positive feedback that enters the system - whether unplanned or deliberately infused by the facilitator or other members-brings difference which-if brought to too-high levels - may threaten to throw the system into chaos or destruction. The facilitator is the one who takes the pulse of the system and attempts to steer it between the two extreme states.

According to the well-known transactional principle (Mead, 1962; Vygotsky, 1978), every intersubjective occurrence has the potential to be intrasubjectively appropriated- 
that is, internalized by each individual member. Thus, not only can punctuated events in the system bring qualitative changes to the whole, but formal and informal patterns of reasoning, argument models, dialogical skills, and even facilitative moves that are triggered between group members tend to become elements of each member's internal repertoire, and are fed back into the system. Because CI is a distributed systemdistributed thinking, distributed intelligence, and distributed authority-the function and roles of the facilitator are spread through the group. As a result, in an ideal mature system, each member shapes the system through both positive and negative feedbackcalling for a summary or a definition, restating, clarifying, identifying connections between ideas, identifying contradictions, attempting to locate the argument, selfcensoring in order to correct imbalances in participation, and so on. Just as each member enters the group with a few spontaneous inquiry behaviors-generalizing, offering counterexamples, and classifying, for example-he or she leaves the ideal community of inquiry having internalized, not just the dispositions of conceptual inquiry, but more process skills, such as evaluating examples, reasoning analogically, judging part whole relationships, and detecting unstated assumptions. Typically in a CI, argument alignment is one of the first internalized products of collective deliberation-an example of which is the preceding of an intervention with "I agree with A's position because ....." or "I disagree with B's idea of....., because ...".

Vygotsky's notion of the zone of proximal development-in this case understood as a collective discursive phenomenon-demonstrates the maxim that "the system is other than the sum of its parts" (Laszlo, 1975, p. 69). In the case of collaborative, dialogical inquiry, the group's distributed intelligence acts as the proximal zone of development for each member, and provides a scaffold for each individual. Furthermore, internalization and scaffolding occur in the psychological and sociological subsystems as well, and individual members play different internalized facilitative roles in the conversation-whether of mediator, negotiator, instigator, or recapitulator. Often, the roles change as the specific activities or the psychodynamics of the group change, which in turn influences the communication system.

System development is a continuously emergent process of reorganization, through individual and group self-correction, which makes its way through the ongoing resolution of the oppositions it encounters, resulting in greater organizational both complexity and clarity. Although its emergence is chaotic, it is characterized by a tendency, to use Prigogine's \& Stengers' (1984) thermodynamic metaphor, to bring "order out of chaos." Rather than maintaining homeostatic stability by rejecting or resisting noise, it develops through accepting and incorporating it in the interest of dialectical emergence. Indeed, in a sense noise incorporation becomes the chief occupation of the system, since noise is an inevitable product of tensions between the various subsystems, between their constituent members, or even between two chronological states in the memory of the system. For an example of the latter, a tension often arises between the habituated patterns of traditional school discourse (teacher as center of group, dispensing turns and questions and affirming and disaffirming student interventions) and the decentered, distributed community of inquiry model. In this case, 
the system's memory is often "holding on to" previous communicative experience, until the internalization of new communicative patterns ensues.

We have discussed the impossibility of avoiding noise in the system, given that it is a product of the tensions between subsystems, between the system and its larger context (the control system of the school, for example), and within the system itself. Noise is endemic to the very idea of system. Some of the oppositions or tensions that produce it take the form of dualities or polarizations, and even of paradoxes. On a more fundamental level, there are structural tensions between part and whole, equilibrium and instability, the internal and the external, the individual and the social, and organism and environment. In addition, dynamic system development aims at both selfpreservation and self-reorganization, and in a system such as CI, there are contradictions of self-reference between the individual and the collective subject: each subjects' identity is possible only through differentiating from the others, but such differentiation is only possible within the context of building an original and ongoing collective identity. The facilitator's role is also paradoxical-she aims both at changing and preserving the system, attempts both to exert and not to exert control, and teaches by not teaching. And transformative system change itself is paradoxical to the extent that it most often results from what we have called a "system event," which is hardly predictable, emergent, and causally overdetermined.

Finally, there are oppositional and dysfunctional tendencies within any system, and the CI system is no exception. One pattern of avoidance of and even rejection of the system's goal, and perhaps the most dangerous in social and political life, is the phenomenon of "groupthink," understood as members' implicit collusion in acting uncritically in order to avoid the risk of conflict and rupture of group cohesiveness. Groupthink is most commonly associated with faulty group decision-making in a specific task, in the performance of which the group relinquishes and rejects any critical analysis of opinions, any search for grounds for inference-making, and any information that is contrary to the group's preferred course of action (Kayton, 1999). Although CI theory understands the creation of a safe group environment as a prerequisite for authentic inquiry, groupthink represents the negative side of group safety, and is a chief inhibitor of inquiry. From a systems perspective, it is associated with stagnation, which temporarily prevents the system from further change.

\section{Conclusion}

As a matrix for collective knowledge construction, the discourse model of CI has potentially important implications as a form of pedagogy, not only for cognitive development but for mental health, for ethical development-i.e. "moral" or "character" education-and for "citizenship" in the sense of the development of democratic skills and dispositions, skills of communal deliberation, and critical consciousness. CI offers the possibility of fulfilling-as much as is possible for a normative ideal-the prerequisites of the Habermasian ideal speech situation. The latter implies a pedagogy that not only develops communicative competence, but which models a form of 
argumentation that understands itself as a cooperative competition in the construction of meaning and understanding - with the major goal of knowledge arrived at collectively through open, free communication. As such, the CI model finds itself in intrinsic contradiction with many of the epistemological and pedagogical assumptions of mainstream schooling. These assumptions include the notion that knowledge is composed of a collection of discrete and quantifiable units; that the unit of analysis in evaluating learning is an abstract, "normed" individual student as opposed either to an idiosyncratic individual or to a group subject; that learning proceeds by building an edifice upon a set of unquestioned assumptions ("basics"), which can only be questioned once the edifice is "complete"; that individual competition drives academic achievement, and that cooperation is a necessary but secondary dimension of classroom discourse; that the unquestioned epistemological authority of the teacher is a sacred necessity of pedagogy; and that individual intelligence is the only relevant form of intelligence there is in the realm of teaching and learning.

All of these assumptions tend to support the social and historical maintenance of a closed or control system, and as such, may be characterized as undemocratic to the extent that they inhibit the ideal speech situation, and ignore the potential of the autopoietic process for optimal individual and group development. They maintain a power/knowledge relationship and a form of subjectification that resists social transformation, and thus maintains mainstream schooling in a set of discourses and practices that have fallen and continue to fall behind the historical evolution of collective intelligence, which is regulated and goaded forward by autopoietic processes. As such, the practice of CI represents a pedagogical innovation with implications for wholesystem change that may be belied by its apparent methodological simplicity.

\section{References}

Ackoff, R. \& Emery, F. (1972). On purposeful systems. Chicago, IL: Aldine.

Ackoff, R. (1958, April). Towards a behavioral theory of communication. Management Science, 4(3): 218234.

Bateson, G. (1972). Steps to an ecology of mind: A revolutionary approach to man's understanding of himself. New York: Ballantine Books.

Corrington, R. (1987). The community of interpreters. Macon, GA: Mercer University Press.

Corrington, R. (1994). The signs of community. In Nature and spirit: An essay in ecstatic naturalism. New York: Fordham University Press.

Davis, B. \& Simmt, E. (2003). Understanding learning systems: Mathematics education and complexity science, Journal for Research in Mathematics Education 34(2): 137-167.

Dewey, J. (1910). How we think. Buffalo, NY: Prometheus Books.

Dewey, J. (1939). Logic: The theory of inquiry. New York: Henry Holt.

Ford, D., \& Lerner, R. (1992). Developmental systems theory: An integrative approach. London: Sage.

Foucault, M. (1979). Discipline and punish (A. Sheridan, Trans.). New York: Vintage.

Habermas, J. (1990). Moral consciousness and communicative action. Cambridge, MA: MIT Press.

Hall, A., \& Fagen, R. (1975). Definition of system. In B. Ruben \& J. Kim (Eds.), General systems theory and human communication (pp. 52-65). Rochelle Park, NJ: Hayden Book Company.

Hand, M., \& Winstanley, C. (2009). Philosophy in schools. London: Continuum.

Kennedy, D. (2004a, Fall). Communal philosophical dialogue and the intersubject. International Journal of Applied Philosophy, 18(2): 203-218. 
Kennedy, D. (2004b, October). The role of a facilitator in a community of philosophical inquiry. Metaphilosophy, 35(5): 744-765.

Kennedy, D. (2006). "What Some Second Graders Say About Conflict." In Changing Conceptions of the Child from Renaissance to Post-Modernity: A Philosophy of Childhood. Lewiston NY: The Edwin Mellen Press.

Kennedy, D. (2008). Helping children develop the skills and dispositions of critical, creative and caring thinking. In M. Gregory et al. (Eds) Philosophy for Children: Practitioner handbook, p. 153-157. Montclair, NJ: Institute for the Advancement of Philosophy for Children.

Kennedy, N.S. (2007). From philosophical to mathematical inquiry in the classroom. Childhood and Philosophy, 3(6): 1-18.

Keyton, J. (1999). Relational communication in groups. In L.Frey (Ed.), The handbook of group communication, theory and practice (pp.192-222). London: Sage.

Kuhn, A. (1975). Social organization. In B. Ruben \& J. Kim (Eds.), General systems theory and human communication (pp. 114-127). Rochelle Park, NJ: Hayden.

Laszlo, E. (1975). Basic constructs of systems philosophy. In B. Ruben \& J. Kim (Eds.), General systems theory and human communication (pp.66-77). Rochelle Park, NJ: Hayden Book Company.

Lipman, M. (2003). Thinking in education. Second Edition. Cambridge: Cambridge University Press.

Lipman, M., Sharp, A., \& Oscanyan, F. (1980). Philosophy in the classroom (2nd ed.). Philadelphia: Temple University Press.

Luhmann, N. (1995). Social systems. (John Bednarz Jr., Dirk Baecker, translators). Stanford: Stanford University Press.

Mead, G. (1962). Mind, self, and society. (C. Morris, ed.). Chicago, IL: The University of Chicago Press.

Maturana, U. (1988). Reality: The search for objectivity or the quest for a compelling argument. The Irish Journal of Psychology, 9(1): 25-82.

Maturana, U., \& Varela, F. (1980). Autopoiesis and cognition. Dordrecht: Reidel.

Maturana, U., \& Varela, F. (1987). The tree of knowledge: The biological roots of human understanding. London: Shambhala.

Peirce, C. S. (1966). The fixation of belief. In P. Weiner (Ed.) Selected writings, pp. 27-40. New York: Dover Publications.

Prigogine, I., \& Stengers, I. (1984). Order out of chaos: Man's new dialogue with nature. New York : Bantam Books.

Shannon, C., \& Weaver, W. (1964). The mathematical theory of communication. Urbana, IL: The University of Illinois Press.

Sharp, A. (1992). What is a community of inquiry? In W. Oxman, N. Michelli \& L. Coia (Eds.), Critical thinking and learning (pp. 295-312). Montclair, NJ: Montclair State University.

Splitter, L. \& Sharp, A. (1995). Teaching for better thinking. Melbourne: ACER.

Varela, F., Maturana, U., \& Uribe, R. (1974). Autopoiesis: The organization of living systems, its characterization and a model. Biosystems, 5: 187-196.

Von Bertalanffy, L. (1968). General system theory. New York: Braziller.

Vygotsky, L. (1978). Mind in society: The development of higher psychological processes (M. Cole, V. JohnSteiner, S. Scribner \& E. Souberman, Eds). Cambridge, MA: Harvard University Press.

Wiggins, G., \& McTighe, J. (2005). Understanding by design. Second Edition. Alexandria VA: Association for Supervision and Curriculum Development.

Wilden, A. (1980). System and structure: Essays in communication and exchange (2nd edition). New York: Tavistock Publications. 


\section{About the Authors}

Nadia Stoyanova Kennedy is Assistant Professor in Mathematics Education at Stony Brook University, USA.nadia@math.stonybrook.edu. Her chief research interest is in the development of curricula and methodologies for school age children that promote open inquiry in mathematics, and which incorporate themes in the philosophy of mathematics.

David Kennedy is Professor in the Department of Educational Foundations at Montclair State University, USA, and Fellow at the Institute for the Advancement of Philosophy for Children. kennedyd@mail.montclair.edu. He is the author of three books and numerous journal articles in the fields of philosophy of childhood and community of philosophical inquiry.

(c) Copyright 2010. The authors, NADIA STOYANOVA KENNEDY and DAVID KENNEDY, assign to the University of Alberta and other educational and non-profit institutions a non-exclusive license to use this document for personal use and in courses of instruction provided that the article is used in full and this copyright statement is reproduced. The authors also grant a non-exclusive license to the University of Alberta to publish this document in full on the World Wide Web, and for the document to be published on mirrors on the World Wide Web. Any other usage is prohibited without the express permission of the authors. 